\title{
19
}

\section{THE PROJECT OF A METROPOLITAN URBAN CENTRALITY}

\section{The Case of the Former Fruit and Vegetable Market of Bologna}

\author{
Paolo Strina
}

The analyses of the state of affairs of the entity-city, through the appraisal of urban phenomena dating back to the 1980s that have consolidated over the last 20 years, judges the failure of an urban planning model based on the expansion of the form that is still in use today, despite the first signs of a countertrend. A consequence of this urban planning practice, based on obsolete zoning concepts, now superseded by the equalization mentality, is the emergence of peripheral "non-places."

To date, the city therefore presents itself as an organism composed of two macro-entities: the periphery and the opposing historic center, an emblem of a compact city that has been the subject of intense debate since the 1960s focused on possible dedicated regeneration policies. A city no longer attributable to a clear and legible formal model but which remains more similar to a gradient the fabric density of which noticeably fades as one moves away from the center and enters the dimension of addition, of conurbation, responding only to infrastructural logic.

The research program "Spinner 2013. Designing the built. New integrated quality models for the compact city," carried out by the group coordinated by Prof. Carlo Quintelli of the University of Parma and subsequently led to the Urban regeneration technique through the structured densification of the centrality system (TDSC), ${ }^{2}$ represents its evolution.

The objective is the formulation of a regeneration method of the contemporary city according to a polycentric logic centered on public space. The result of the research is an "analysis-metaproject-urban project" process technique that exploits the presence of a vast resource of empty but already built space (urbanized voids) inside the shaped city, potentially densifiable through the settlement of complex architectural typologies with a prevalently public character, defined as urban centralities (Figure 19.1).

The transcalar analysis of the shaped city, built upstream of the research work, brings to light an anatomy of the urban body composed of areas of a prevalent functional character, centrality factors coinciding with public or private amenities and equipment for public use, and centrality fields ${ }^{3}$ intended as polarizing basins. 


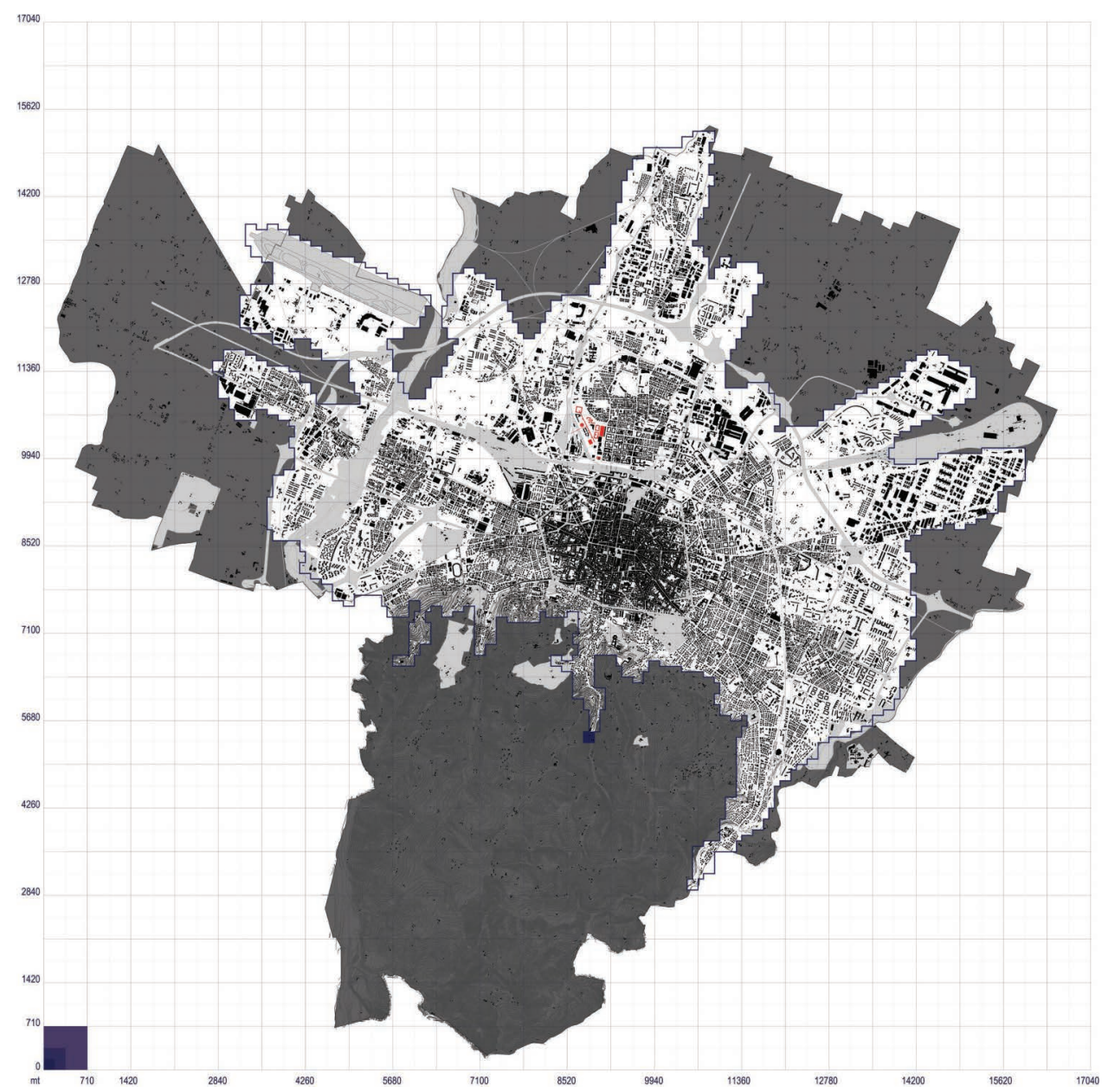

FIGURE 19.1 The shaped city of Bologna with (in red) the project masterplan of the new metropolitan-type urban centrality (scale 1:20000).

The so-called spaces for the urban centrality of the project are selected within the fields of centrality, according to the morpho-typological conditions filtered according to accessibility, visibility, and usability factors.

The space, based on the nature of the context in which it is established and the types of urban relations it triggers or enhances, takes on three different roles:

A. Urban centrality in a polycentric relationship system;

B. Metropolitan urban centrality;

C. Urban centrality of parts of the city;

During the research and in subsequent didactic experiments, all the three different central roles were studied in depth. 
The ArchéA research program provided the opportunity to verify and refine the TDSC technique, through the regeneration project of the former fruit and vegetable market of Bologna developed during the Architectural Design Workshop held at the Faculty of Architecture Bologna-Cesena from November 23 to November 30, 2019.

The application of the TDSC technique to the project context, gradually from the large territorial scale to the more restricted one of the project, has suggested the application of the metropolitan-type urban centrality intended as a link between hinterland and city, between the metropolitan and urban landscape, having a predominantly directional function able to "govern" the vast area of reference. It is therefore evident that urban centrality of a metropolitan type is established within a city, an area and a field of centrality with a high intrinsic metropolitan vocation, a condition that is certainly detectable both in the city of Bologna,

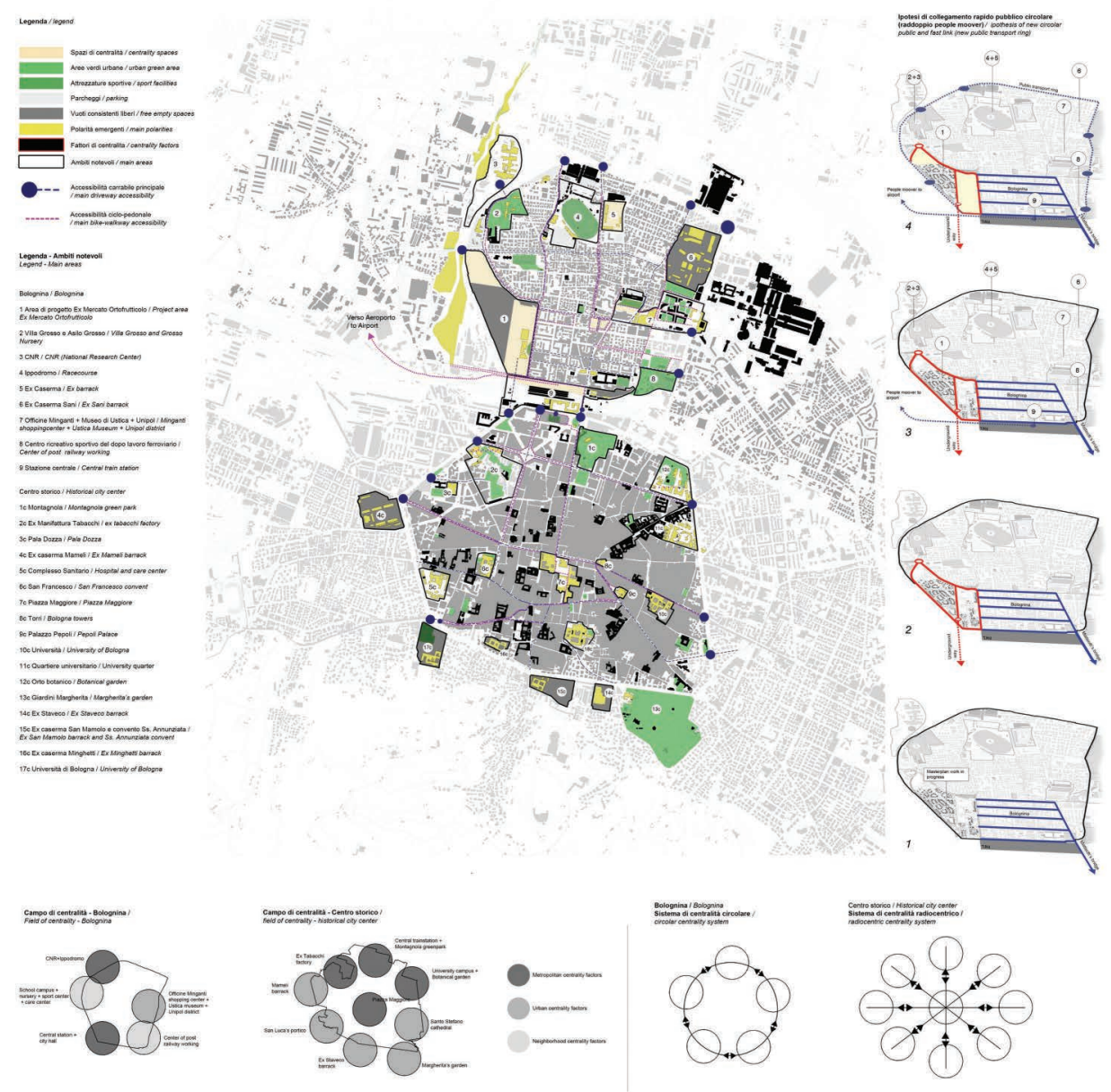

FIGURE 19.2 Relational analysis of the "Bolognina" and Historic Center fields of centrality, in which the factors of centrality emerge. On the right shoulder and in the space below the table, the layouts of the project's circular metropolitan centrality supported by an ideal system of annular mobility (scale 1:10000). 
which became a Metropolitan City in $2014,{ }^{4}$ and in the "Bolognina" district, where the chosen project area continues.

The application of the TDSC technique to the objective of the workshop led to assume the "Bolognina" district itself as a dominant central area within a highly infrastructured area, in close contact with the hinterland thanks to the presence of the motorway exit tollbooth toward the fair district and endowed with centrality factors of metropolitan character such as the railway station, the axis of via Stalingrado, the motorway belt, the fair district itself, the headquarters of the National Research Centre, the Hippodrome, and the new headquarters of the Town Hall. The urban value of the Bolognina centrality field is strengthened by the close proximity to the historic center to which it is connected by the Central Station system and the Matteotti Bridge (Figure 19.2).

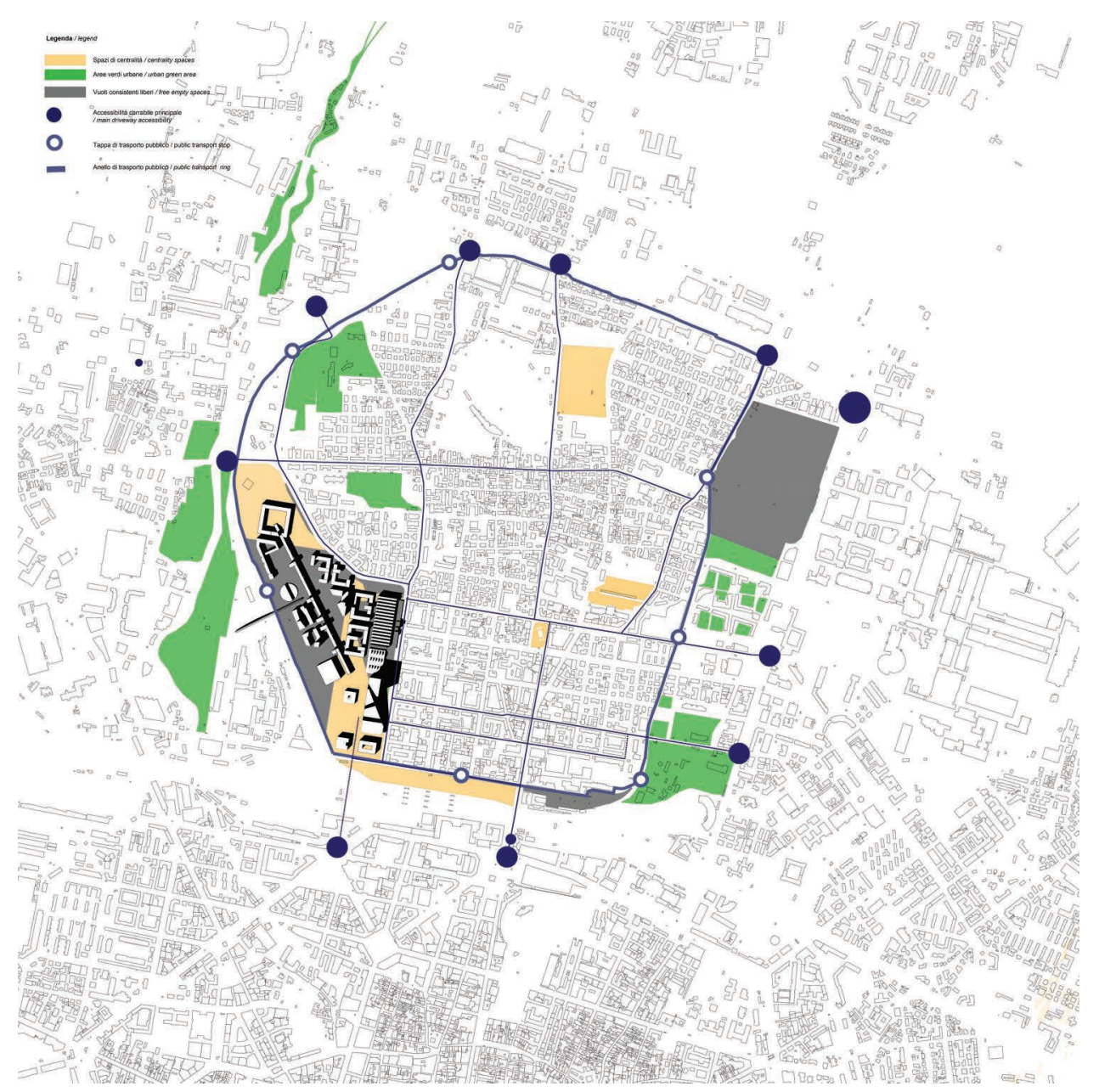

FIGURE 19.3 The structure of the "Bolognina" centrality field, highlighting the annular mobility layout with respect to which the new metropolitan-type urban centrality project is established (scale 1:5000). 


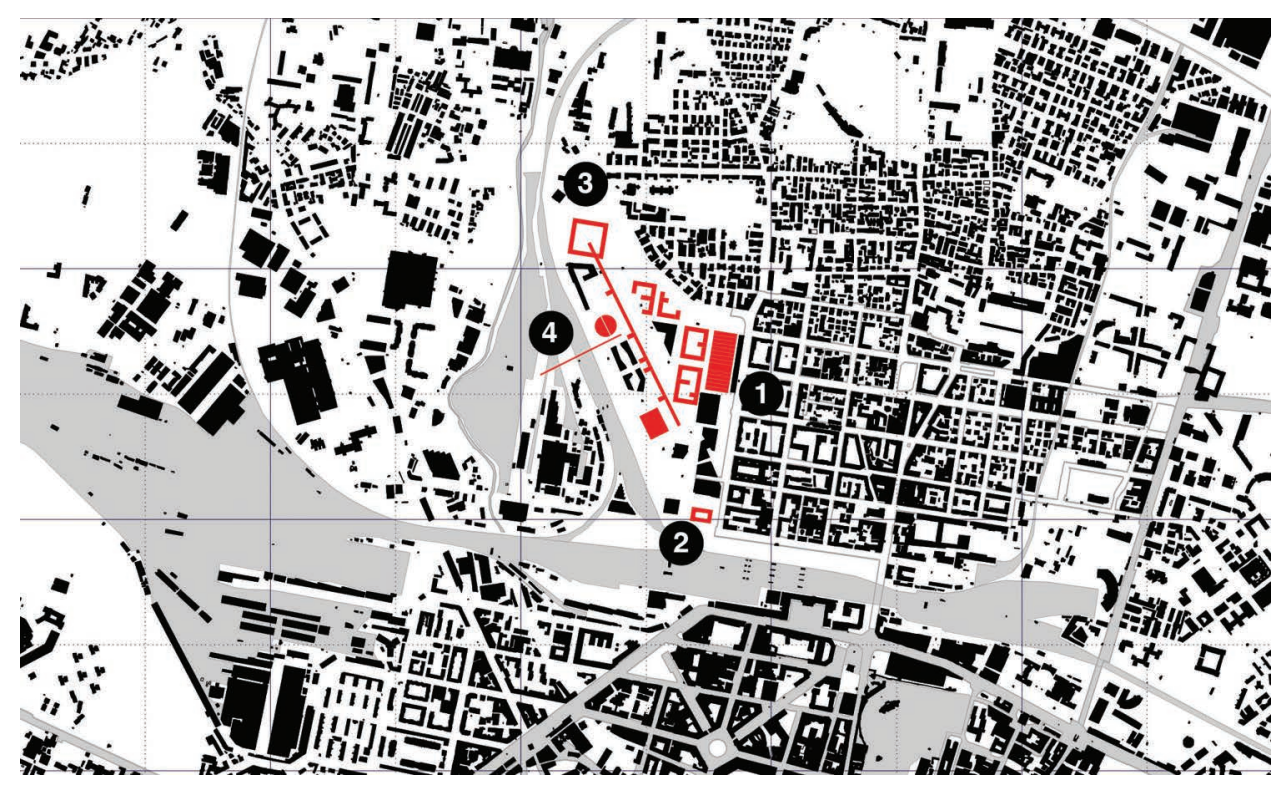

FIGURE 19.4 Aerial view of the project area with the four main subareas of strength of the project established (1 - periphery toward the historic "Bolognina"; 2 - confluence on via dei Carracci adjacent to the railway station; 3 - North confluence toward the CNR [National Research Center]; 4 - naturalistic periphery toward the Parco del Navile).

This plural coexistence of characteristics gives metropolitan value to the project context in which to establish and experience a new metropolitan centrality that amplifies the management role intrinsic to the entire area.

The structure of the "Bolognina" centrality field consists of a Cardo and Decumanus system centered in Piazza dell'Unità, with respect to which the orthogonality of the NorthSouth and East-West connections develops between the spaces responsible for internal usability of the field itself. This system interfaces with a series of centrality factors located on the edge of the field and configures a type of ring-shaped centrality space, composed of several fragments, including the former fruit and vegetable market (Figure 19.3).

The project area appears as a large urban void already strongly and irreversibly urbanized. The first objective of the project is the hierarchization of the space into specialized subspaces, within which to operate a new linear urban centrality consisting of interlinked polarities, capable of consolidating and regenerating the urban structure of the "Bolognina" neighborhood and strengthening the relationships between peripheral components (Figure 19.4).

From these premises, four main subareas of the project area have been identified:

1. The dense eastern periphery overlooking the historical fabric of "Bolognina", characterized by the presence of the new Town Hall, the Nervi Pavilion, and the multistory car park. The said periphery is flanked by a primary road with respect to the vehicular traffic parked at the new municipal headquarters and directed toward the northern outskirts. The front of this periphery is strengthened by the preexisting monumental entrance portal to the old market, a perspective focus with respect to the East-West axes coming from via Stalingrado toward Canale Navile; 
2. The confluence on via De 'Carracci, the link between the level area of the High Speed Station and the project area. In it converges the ascent from the vehicle underpass coming from the city center and directed to the Kiss and Ride of the High Speed and to the center of the project area;

3. The North confluence, a bonding point between the project area and the peripheral landscape of the National Research Centre strongly influenced by the naturalistic preexistence of the Navile canal;

4. The natural boundary adhering to the Navile Park.

The cornerstones of the new metropolitan-type urban centrality are located in the four subareas of the project area, respecting the buildings already built in the first phase of implementation of the Masterplan approved by the Municipality of Bologna and only partially completed to date.

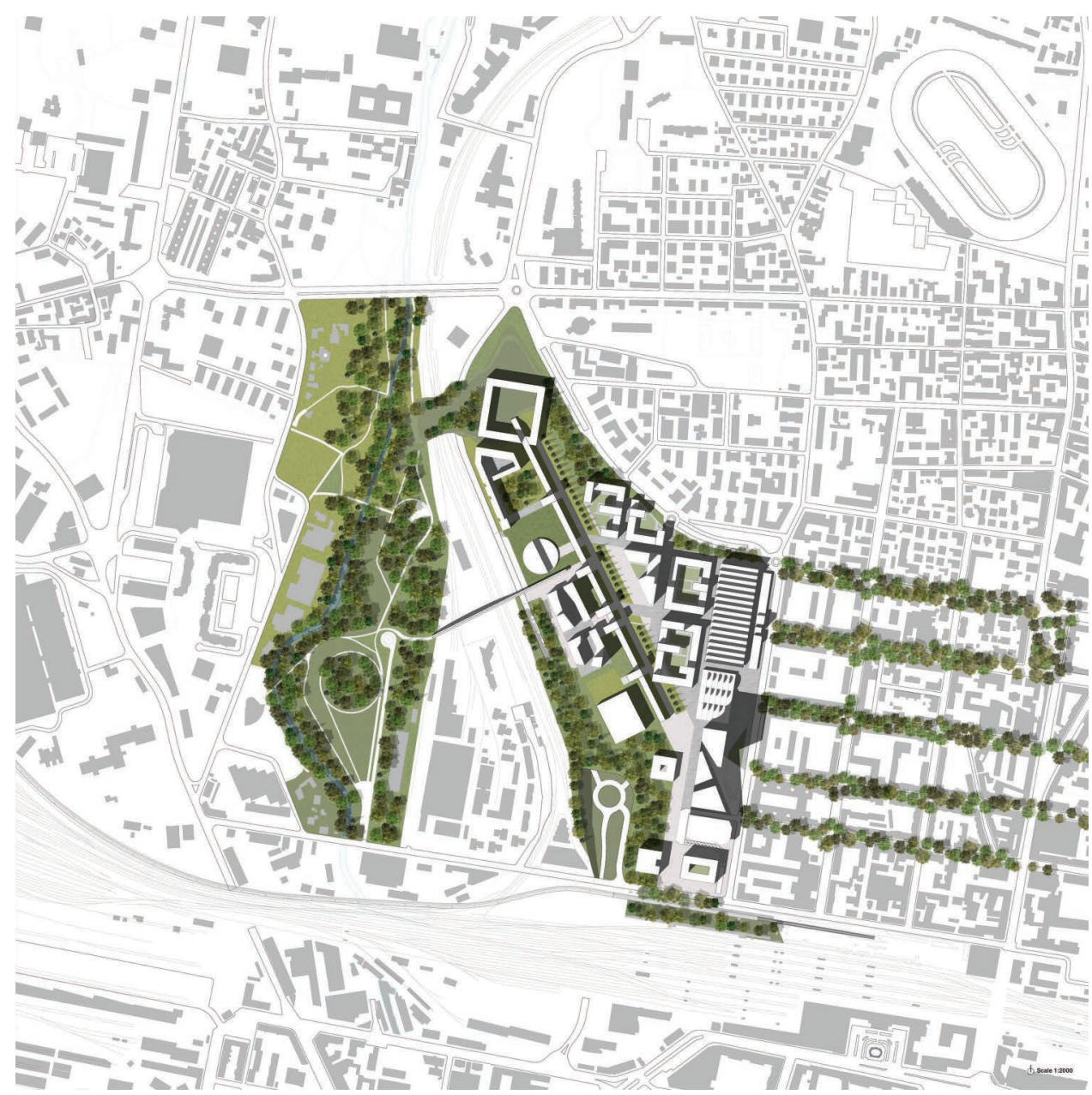

FIGURE 19.5 Volumetric plan of the project (scale 1:2000). 
The result is a paratactic composition originating from the square in front of the new Town Hall.

Accessibility is guaranteed from the Town Hall itself and from the entrance portal to the south, facing Via Carracci, by flanking an existing office building with a courtyard residential block with related services.

The square effect is obtained by introducing a building hosting the gymnasium that at the same time circumscribes the space in a smaller and more typical dimension of the consolidated city. From the square stands a regulating axis that extends the perspective diagonal dictated by the covered space of the new Town Hall: a real linear arcaded building with tertiary functions on the upper floors that divides the project area into two complementary parts: the one adjacent to the Parco del Navile and the one most in contact with the compact historical fabric of "Bolognina" (Figure 19.5).

The more public functions are concentrated toward the Parco del Navile, such as the school complex and the multipurpose center, autonomous, punctual, and linguistically
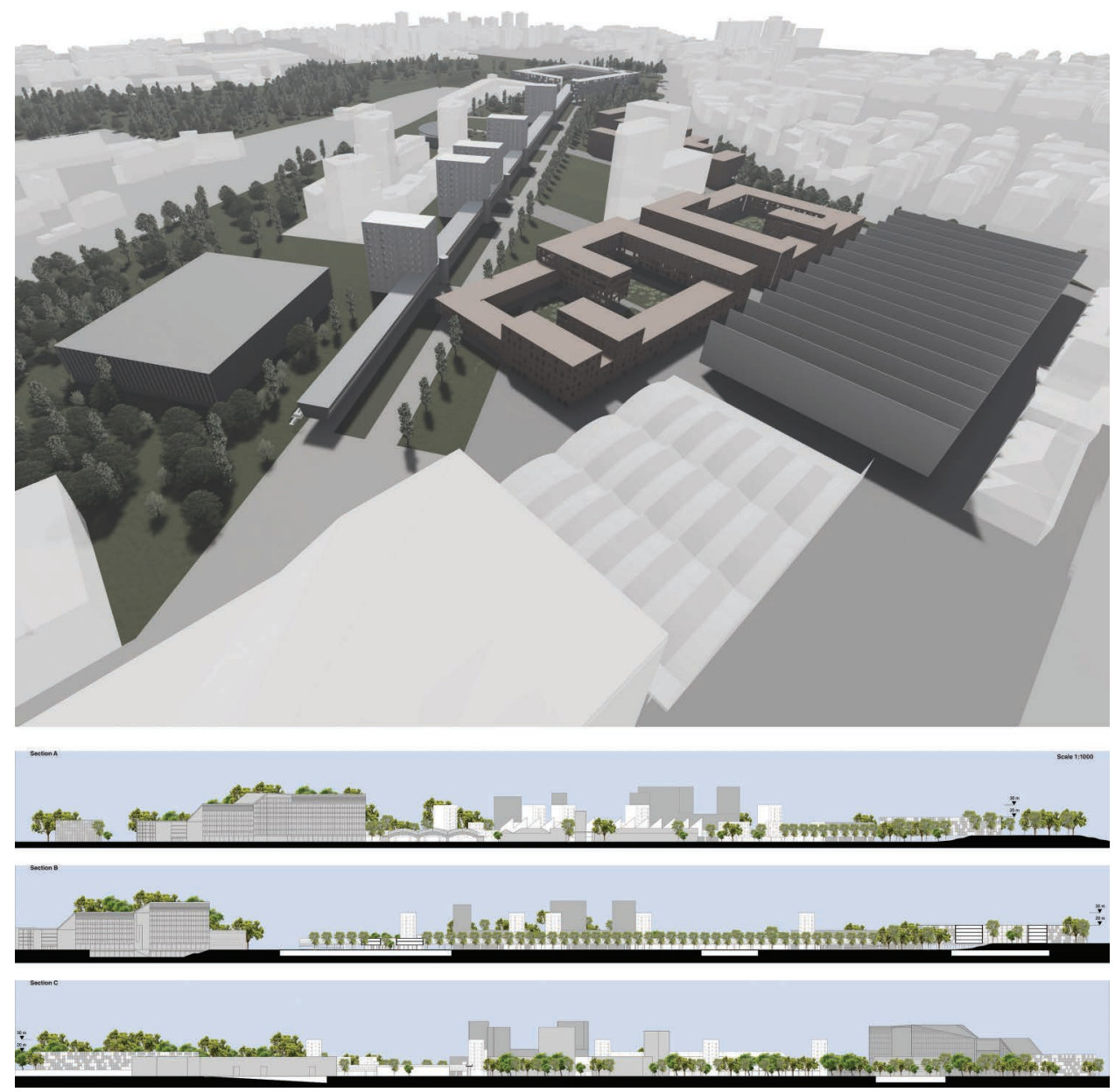

FIGURE 19.6 Aerial view and environmental sections of the project. 
more similar elements to the naturalistic context with which they relate. The residential courtyards are concentrated toward the compact and consolidated fabric of historic Bolognina, which replicate the typical morphology of the neighborhood, mitigating the impact on the identity level. The punctual elements on the front of the Navile, together with the articulations of the residential courtyards on the front of the historic Bolognina, configure rest areas along the architectural promenade in correspondence with significant elements such as the school complex, the multipurpose center, and the bridge connecting the axis matrix and the Parco del Navile. Corresponding to these "open spaces," there are residential tower blocks attached to the built axis, the portico of which is fundamental with respect to the maximum permeability between the project areas. The regulating axis culminates in the north with a highly monumental, stereometric, monolithic, and highly visible confluence element: the large courtyard hosting types of specialized residences and a hotel. The project
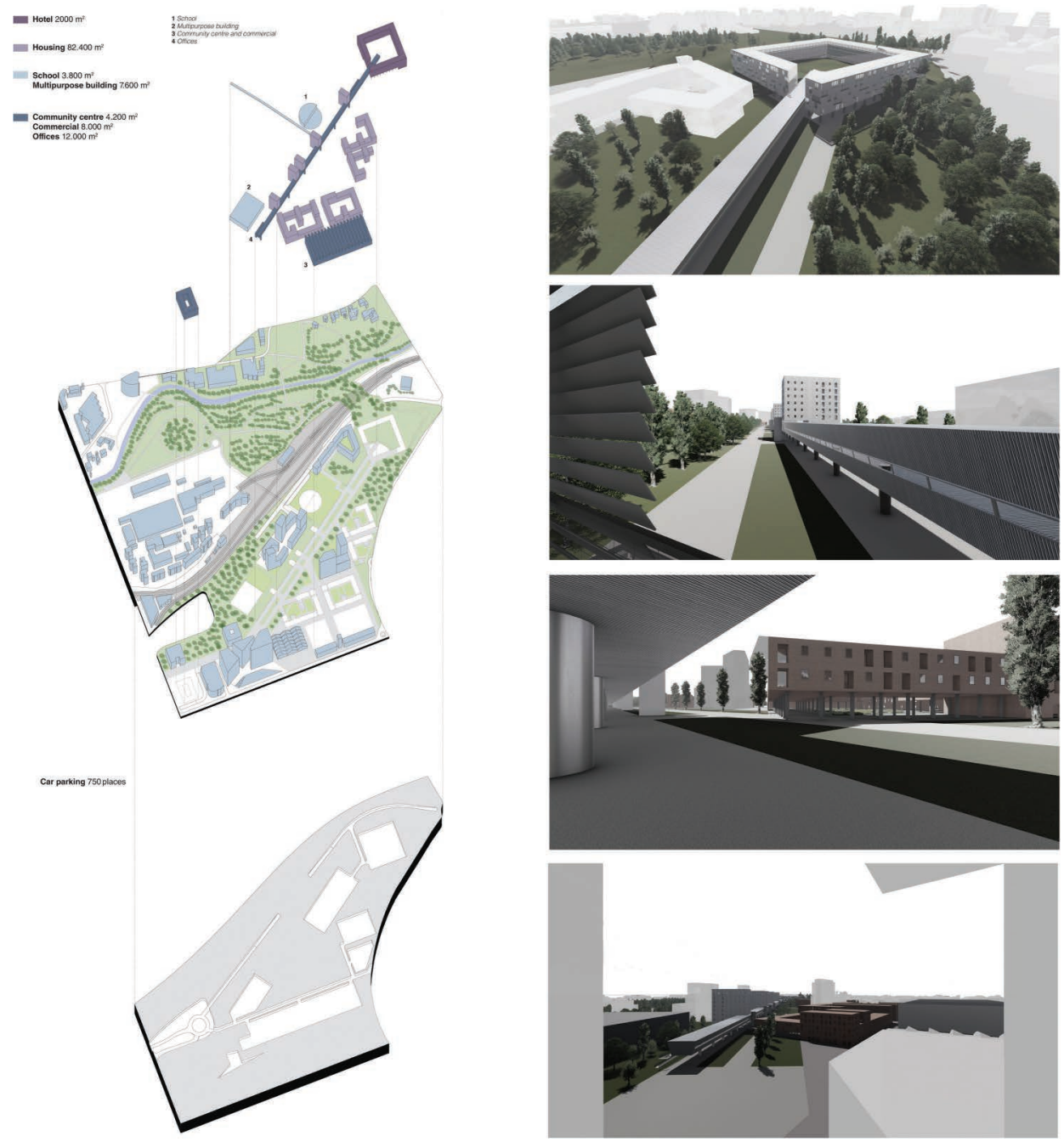

FIGURE 19.7 Functional stratigraphic axonometry and views of the project. 
matrix is superimposed on a second pattern of routes coming from the "Bolognina" fabric, which are articulated between the new residential courtyards. This more urban landscape finds in the new building used as a covered market the connecting element between the historic "Bolognina" and the new centrality.

The building in question, placed at the end of the "enfilade" periphery toward the neighborhood, strengthens the public space as a filter between two realities. This is configured as an elevated slab that organizes functional levels: the ground floor imagined as a large cover with a giant staircase that underlies the market; the upper floors, on the other hand, host commercial and tertiary businesses and the community center. The elevation of the new slab with shed roof strengthens the front on the Bolognina, placing itself as a linear and silent background to the tower of the entrance portal to the former fruit and vegetable market, preserved and recovered as an opening to the new hypostyle space (Figure 19.6).

The project is completed with a level of vehicular traffic and totally underground parking, in continuity with the underpass coming from the historic center of Bologna already partially built. This choice is inclined toward the ideal of the "car-free" metropolitan urban centrality, in which the level of public space is at the complete disposal of the inhabitant for a type of cycle-pedestrian use between paved surfaces and equipped green areas (Figure 19.7).

*Project by Enrico Prandi (scientific manager) with Carlo Gandolfi, Paolo Strina (coordinating tutor), and Giuseppe Verterame. Students: Isabel Chiesa, Davide Fabbi, Ernesto Frigerio, Camilla Garagna, Irene Di Santo, and Antonio Villa.

\section{Notes}

1 The research project was financed by the Emilia Romagna Region with a doctoral scholarship that led to the thesis of Strina, P. Densification techniques through the metropolitan urban centralities strategy, in addition to those of Nolli, A. Densification techniques through the urban centralities strategy centred on a polycentric relationship system, and Montini, N. Densification techniques through the urban centralities strategy of parts of the city (supervisor, Quintelli C., 2015). The research, under the scientific direction of Carlo Quintelli with Enrico Prandi and Paolo Strina and the collaboration of G. Verterame, is undergoing a methodological study with the aim of a forthcoming publication for the types of Il Poligrafo, Padua.

2 For a concise explanation of the TDSC technique, see Enrico Prandi's essay in this book.

3 Perimeter area through the peripheral component susceptible to transformation through the implementation of new urban centres. The intrinsic potential of the field is measured based on the quantity and quality of centrality factors present in it and their synergistic relationship modalities through the morphological conditions that symbolise the field.

Definition taken from the doctoral thesis of P. Strina, Densification technique through the metropolitan type urban centralities strategy, p. 375.

4 In Italy, a law modifying the administrative structure has led to the establishment of the metropolitan cities. See Law April 7, 2014, n. 56, "Provisions on metropolitan cities, provinces, on the union and mergers of municipalities," called the Delrio Law from the name of its author. 